\title{
PRODUTIVIDADE E QUALIDADE DE FRUTOS DE MAMÃO CULTIVAR 'GOLDEN' SOB DIFERENTES LÂMINAS DE IRRIGAÇÃO E DOSES DE POTÁSSIO NO NORTE DE ESPÍRITO SANTO ${ }^{1}$
}

\author{
ALBANISE B. MARINHO ${ }^{2}$, SALASSIER BERNARDO ${ }^{3}$, ELIAS F. DE SOUSA ${ }^{4}$, \\ MESSIAS G. PEREIRA ${ }^{5}$, PEDRO H. MONNERAT ${ }^{6}$
}

\begin{abstract}
RESUMO: Este trabalho teve como objetivo estudar os efeitos de diferentes lâminas de irrigação e de doses de potássio sobre a produtividade e a qualidade dos frutos do mamoeiro cultivar Golden. $\mathrm{O}$ experimento foi realizado em área de produção agrícola comercial, localizada em Linhares - ES. O delineamento experimental foi em blocos casualizados, com arranjo em parcela subdividida, com três repetições. Os tratamentos foram compostos por cinco lâminas de irrigação, na parcela, e quatro doses de potássio, na subparcela, totalizando 20 tratamentos. As cinco lâminas de irrigação programadas foram de 50; 70; $90 ; 110$ e $130 \%$ da ETo, e as quatro doses de potássio foram de 30; 42; 54 e $66 \mathrm{~g}$ de $\mathrm{K}_{2} \mathrm{O}$ por planta ao mês. Os elevados índices pluviométricos no período experimental (fevereiro-2005 a junho-2006) excederam em muito as necessidades hídricas das plantas, interferindo nos tratamentos, não permitindo variação significativa nas variáveis analisadas, principalmente em função das lâminas aplicadas. Durante os 11 meses e 21 dias de colheita, a produtividade média da cultivar Golden foi de 79,4 t ha ${ }^{-1}$, com média de 96 frutos por planta, que, no estádio I de maturação, apresentavam massa de $404 \mathrm{~g}$, teor médio de SST de $10,11^{\circ}$ Brix e firmeza da polpa e do fruto de $79,80 \mathrm{~N}$ e $126,19 \mathrm{~N}$, respectivamente.
\end{abstract}

PALAVRAS-CHAVE: irrigação, produção, nutrição de plantas.

\section{FRUIT YIELD AND QUALITY OF PAPAYA 'GOLDEN' UNDER DIFFERENT IRRIGATION DEPTHS AND POTASSIUM DOSES IN THE NORTH OF ESPIRITO SANTO STATE, BRAZIL}

\begin{abstract}
This work aimed to study the effects of different irrigation depths and potassium doses on yield and fruit quality of papaya cv Golden. The experiment was carried out in an area of commercial and agricultural production situated in Linhares - ES, Brazil. The design employed was randomized blocks, arranged in subdivided parcels and having three replications. The treatments consisted of five irrigation depths in the parcel and four potassium doses in the subparcel, totalizing 20 treatments. The five programmed irrigation depths were $50 ; 70 ; 90 ; 110$ and $130 \%$ of the reference evapotranspiration and the four potassium doses were $30 ; 42 ; 54$ and $66 \mathrm{~g} \mathrm{of} \mathrm{K}_{2} \mathrm{O}$ plant $^{-1}$ month $^{-1}$. The high rainfall rates in the experimental period (February-2005 to June-2006), greatly overcame the plant water requirements, interfering in the treatments, not allowing significant variation in the variables analyzed, particularly in function of the applied depths. During the 11 months and 21 days of harvest, the average yield was $79.41 \mathrm{t} \mathrm{ha}^{-1}$, with an average of 96 fruits per plant which, in the first stage of ripening, presented a mass of $404 \mathrm{~g}$, average total soluble solids content (SST) of $10.11^{\circ}$ Brix and pulp and fruit firmness of $79.80 \mathrm{~N}$ and $126.19 \mathrm{~N}$, respectively.
\end{abstract}

KEYWORDS: irrigation, production, plant nutrition.

\footnotetext{
${ }^{1}$ Extraído da Tese de Doutorado do primeiro autor.

${ }^{2}$ Eng $^{\mathrm{a}}$ Agrícola, Doutor, LEAG/CCTA/UENF, Campos dos Goytacazes - RJ, Fone (0XX22) 2726.1607, albanise@gmail.com

${ }^{3}$ Eng $^{0}$ Agrônomo, Prof.Titular, Ph.D, LEAG/CCTA/UENF, Campos dos Goytacazes - RJ.

${ }^{4}$ Eng 9 Agrônomo, Prof. Associado, Doutor, LEAG/CCTA/UENF, Campos dos Goytacazes - RJ.

${ }^{5}$ Eng ${ }^{0}$ Agrônomo, Prof. Associado, Ph.D, LMGV/CCTA/UENF, Campos dos Goytacazes - RJ.

${ }^{6}$ Eng ${ }^{\mathrm{o}}$ Agrônomo, Prof. Titular, Ph.D, LFIT/CCTA/UENF, Campos dos Goytacazes - RJ.

Recebido pelo Conselho Editorial em: 29-5-2007
}

Aprovado pelo Conselho Editorial em: 3-6-2008 


\section{INTRODUÇÃO}

O cultivo do mamão responde significativamente ao uso da irrigação suplementar nas regiões com precipitações inferiores a $1.500 \mathrm{~mm}$ por ano, ou mesmo com precipitações superiores, mas distribuídas irregularmente. Em regiões com precipitações anuais inferiores a $1.000 \mathrm{~mm}$, o uso da irrigação é fundamental ao cultivo racional e econômico do mamoeiro (BERNARDO et al., 1996). Em regiões onde ocorrem veranicos prolongados, a cultura não apresenta rendimentos satisfatórios sem o uso da irrigação (COELHO \& SILVA, 2003).

ALMEIDA et al. (2003) verificaram que, nas condições climáticas do Norte Fluminense, a lâmina total de água que promoveu a maior produção de frutos de mamão foi de $2.937 \mathrm{~mm}$; no entanto, lâminas aplicadas entre 2.074 e $2.937 \mathrm{~mm}$ proporcionaram incremento de produção muito pequeno. SILVA et al. (2001), nas condições climáticas do norte do Espírito Santo, verificaram que a produtividade máxima ocorreu para a lâmina aplicada de $2.731 \mathrm{~mm}$.

Para obter alta produtividade e boa qualidade dos frutos do mamoeiro, é necessário um conjunto de fatores, como luz, temperatura, solo, $\mathrm{CO}_{2}$, água e nutrientes. A ação conjunta desses fatores influenciará nas taxas de crescimento e de produtividade, garantindo o desenvolvimento e a qualidade dos frutos (MARTINS \& COSTA, 2003).

As quantidades e as relações entre nutrientes necessários para o mamoeiro ainda não estão bem definidas. Ao potássio $(\mathrm{K})$ é atribuído o efeito na concentração de açúcares e sólidos solúveis totais no fruto, o que reflete na qualidade. $\mathrm{O}$ fornecimento de nitrogênio $(\mathrm{N})$ está relacionado aos maiores aumentos na produtividade do mamoeiro. $\mathrm{O}$ fósforo $(\mathrm{P})$ é considerado de grande importância para o desenvolvimento radicular e para a fixação dos frutos. A relação $\mathrm{N} / \mathrm{K}_{2} \mathrm{O}$ influencia na consistência da polpa, o que determina maior ou menor resistência ao transporte (VITTI, 1989). OLIVEIRA et al. (2004) recomendam que, nas adubações do mamoeiro, a relação dos nutrientes seja próxima de 1 .

Trabalhos sobre adubação potássica no mamoeiro, realizados por OLIVEIRA \& CALDAS (2004), em Cruz das Almas - BA, e por SANTOS (2006), em Limoeiro do Norte - CE, mostraram que a aplicação de 42,67 e $75 \mathrm{~kg}$ de $\mathrm{K}_{2} \mathrm{O} \mathrm{ha}{ }^{-1}$ mês $^{-1}$, respectivamente, proporcionou maiores produtividades.

As qualidades dos frutos de mamão podem ser avaliadas por vários parâmetros, sejam eles físicos, como peso, comprimento, diâmetro, forma, cor e firmeza, sejam químicos, como sólidos solúveis totais (SST), pH, acidez titulável e outros (FAGUNDES \& YAMANISHI, 2001). Geralmente, essas características podem ser influenciadas por fatores como: condições edafoclimáticas, cultivar, época e local de colheita, tratos culturais e manuseio na colheita e na póscolheita. A firmeza do fruto é atributo de qualidade que pode indicar o seu estádio de maturação ou ponto de colheita e que influencia na sua comercialização. Além das características genéticas que condicionam a firmeza dos frutos, a nutrição da planta, a disponibilidade de água no solo e o estádio de maturação dos frutos também afetam essa característica. MALAVOLTA et al. (1997) afirmam que o aumento de doses de fertilizantes, com o objetivo de elevar a produção, pode provocar redução na qualidade dos frutos, afetando o tamanho, a resistência ao transporte e ao armazenamento, a coloração interna e o teor de sólidos solúveis dos frutos.

O fornecimento de água e de nutrientes às culturas em proporções adequadas tem sido uma das maiores dificuldades enfrentadas pelos produtores. Assim, os objetivos deste trabalho foram estudar os efeitos de diferentes lâminas de irrigação e doses de potássio na produção e nas características físicas e químicas dos frutos do mamoeiro cultivar Golden, nas condições climáticas do norte do Espírito Santo.

\section{MATERIAL E MÉTODOS}

O experimento foi conduzido em área de produção agrícola comercial, localizada no

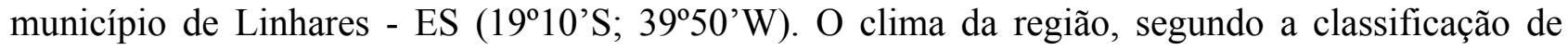


Köeppen, pertence ao grupo Awi, apresentando estação chuvosa no verão e seca no inverno, com precipitação média anual de $1.250 \mathrm{~mm}$, temperatura média de $23{ }^{\circ} \mathrm{C}$, com máxima de $30{ }^{\circ} \mathrm{C}$ e mínima de $19^{\circ} \mathrm{C}$, e umidade relativa de 83,5\% (ROLLIN et al., 1999; SIAG, 2006). O solo da área experimental é classificado como Latossolo Vermelho-Amarelo distrófico, coeso e bem drenado, com textura arenosa, fase floresta subperenifólia, relevo plano e suavemente ondulado (platôs litorâneos), cujas características químicas e hídricas estão apresentadas nas Tabelas 1 e 2.

A caracterização química do solo foi feita antes da aplicação dos tratamentos e no final do experimento, mediante análises de amostras coletadas na camada de 0,0-0,30 m de profundidade. No início do experimento, a amostragem foi de toda a área e, no final do experimento, as análises de solo foram realizadas em função das adubações potássicas, haja vista que, devido ao excesso de chuvas, não houve diferenciação em função das lâminas aplicadas. Na Tabela 1, têm-se os teores médios dos nutrientes no solo da área experimental.

TABELA 1. Resultados das análises químicas do solo. Results of the soil chemical analysis.

\begin{tabular}{|c|c|c|c|c|c|c|c|c|c|c|c|c|c|}
\hline \multicolumn{14}{|c|}{ Início do Experimento } \\
\hline \multirow{2}{*}{\multicolumn{2}{|c|}{$\left(\mathrm{mg} \mathrm{dm}^{-3}\right)$}} & $\mathrm{S}$ & $\mathrm{Ca}$ & $\mathrm{Mg}$ & $\mathrm{Al}$ & $\mathrm{H}+\mathrm{Al}$ & \multirow{2}{*}{\multicolumn{2}{|c|}{$\begin{array}{cc}\mathrm{pH} & \mathrm{MO} \\
\mathrm{g} \mathrm{kg}^{-1}\end{array}$}} & SB & $\mathrm{t}$ & $\mathrm{T}$ & $\mathrm{V}$ & $\mathrm{m}$ \\
\hline & & \multicolumn{5}{|c|}{$\left(\right.$ mmolc $\left.\mathrm{dm}^{-3}\right)$} & & & \multicolumn{3}{|c|}{$\left(\right.$ mmolc dm $\left.{ }^{-3}\right)$} & \multicolumn{2}{|c|}{$(\%)$} \\
\hline 64,0 & 38,0 & 5,0 & 1,8 & 0,9 & 0,0 & 2,2 & 6,3 & 22,0 & 28,0 & 28,0 & 50,0 & 0,0 & 56,0 \\
\hline \multicolumn{14}{|c|}{ Final do Experimento } \\
\hline 5,8 & 382 & 111 & 7,7 & 1,0 & 7,5 & 58,8 & 4,3 & 17,8 & 22,9 & 30,4 & 81,7 & 24,8 & 28,0 \\
\hline
\end{tabular}

TABELA 2. Características físico-hídricas de amostras de solo da área experimental. Physicohidrical characteristics of soil samples in the experimental area.

\begin{tabular}{ccccc}
\hline $\begin{array}{c}\text { Profundidade } \\
(\mathrm{cm})\end{array}$ & $\mathrm{CC}$ & PMP & $\begin{array}{c}\text { Densidade Aparente } \\
\left(\mathrm{kg} \mathrm{m}^{-3}\right)\end{array}$ \\
\cline { 2 - 4 } $2-20$ & 0,232 & & 0,121 & 1.476 \\
$20-40$ & 0,232 & 0,135 & 1.491 \\
\hline
\end{tabular}

Utilizou-se do mamoeiro, cultivar Golden, plantado em fileiras duplas no espaçamento 3,6 x $2,0 \times 1,8 \mathrm{~m}$. A semeadura foi feita em saquinhos em 20-9-2004, cuja germinação ocorreu entre os dias 28 e 31 de setembro. O transplantio das mudas para o campo foi realizado em 20-10-2004, e a sexagem, no período de $1^{\circ}$ a 16-2-2005 (125 dias após o transplantio - DAT). As adubações básicas de plantio e formação foram realizadas de acordo com o manejo da Fazenda. No transplantio das mudas, a adubação foi à base de fósforo ( $250 \mathrm{~g}$ por metro de superfosfato simples); aos 30 dias após o transplantio (DAT), adubou-se com $30 \mathrm{~g} \mathrm{planta}^{-1}$ de sulfato de amônio e, após a sexagem, realizou-se adubação química com N:P:K (100 $\mathrm{g} \mathrm{planta}^{-1}$ de sulfato de amônio; $100 \mathrm{~g} \mathrm{planta}^{-1}$ de superfosfato simples e $50 \mathrm{~g}_{\text {planta }}{ }^{-1}$ de cloreto de potássio).

O delineamento utilizado foi em blocos casualizados, com arranjo em parcela subdividida, com três repetições. Os tratamentos foram constituídos de cinco lâminas de irrigação (parcela) e quatro doses de potássio (subparcela). Cada unidade experimental, com 120,96 $\mathrm{m}^{2}$, foi constituída de oito plantas úteis e 16 de bordadura. As lâminas de irrigação programadas foram: $\mathrm{L}_{1}=50 \% \mathrm{ETo}$; $\mathrm{L}_{2}=70 \% \mathrm{ETo} ; \mathrm{L}_{3}=90 \% \mathrm{ETo} ; \mathrm{L}_{4}=110 \% \mathrm{ETo}$, e $\mathrm{L}_{5}=130 \% \mathrm{ETo}$, aplicadas diariamente, de segunda a sexta-feira. A evapotranspiração de referência (ETo) foi estimada a partir da equação de Penman-Monteith-FAO (ALLEN et al., 1998). Devido ao excesso de chuvas no período $(2.020 \mathrm{~mm})$, as lâminas totais aplicadas, referentes aos tratamentos propostos (irrigação mais precipitação efetiva, $\mathrm{I}+\mathrm{Pe}$ ) foram: $\mathrm{L}_{1}=1.236 \mathrm{~mm} ; \mathrm{L}_{2}=1.339 \mathrm{~mm} ; \mathrm{L}_{3}=1.444 \mathrm{~mm} ; \mathrm{L}_{4}=1.525 \mathrm{~mm}$ e $\mathrm{L}_{5}=1.604 \mathrm{~mm}$. As adubações diferenciadas com $\mathrm{K}$ foram definidas com base na recomendação de adubação potássica da Fazenda, usando como referência $83 \mathrm{~g}$ de $\mathrm{KCl}$ por planta ao mês $(49,9 \mathrm{~g}$ de $\mathrm{K}_{2} \mathrm{O}$ ). As doses de $\mathrm{K}$ foram: $\mathrm{K}_{1}=30 ; \mathrm{K}_{2}=42 ; \mathrm{K}_{3}=54$, e $\mathrm{K}_{4}=66$, aplicadas em $\mathrm{g}$ de $\mathrm{K}_{2} \mathrm{O}$ por planta ao mês, na forma de cloreto de potássio, por cobertura, adubadas mensalmente. 
O sistema de irrigação utilizado foi microaspersão, com um microaspersor para cada quatro plantas. Foi utilizado o microaspersor autocompensante da Netafim-Supernet LR, com vazão média determinada em campo de $59 \mathrm{~L} \mathrm{~h}^{-1}$, para pressão de serviço média de 20 mca. A demanda hídrica foi calculada por meio da eq.(1):

$$
\mathrm{V}=\{[(\mathrm{ETo} \mathrm{Kc})-\mathrm{Pe}] \mathrm{f}\} \frac{\mathrm{Np} \mathrm{Ap} \mathrm{Pw}}{\mathrm{Ea}}
$$

em que,

V - volume de água aplicado por tratamento, L;

ETo - evapotranspiração de referência acumulada desde o último cálculo da lâmina aplicada (mm), obtida pela estação micrometeorológica, instalada na Fazenda;

Kc - coeficiente de cultura, em função da idade da cultura, adimensional;

Pe - precipitação efetiva acumulada desde o último cálculo da lâmina aplicada, mm;

f - percentagem da lâmina definida pelo tratamento, que corresponde a 50; 70; 90; 110 e 130 da ETo, adimensional;

$\mathrm{Np}$ - número de plantas irrigadas por microaspersor, quatro plantas;

Ap - área ocupada pela planta $\left(5,04 \mathrm{~m}^{2}\right)$;

$\mathrm{Pw}$ - percentagem de área molhada, $(60 \%)$, definida a partir das características do microaspersor e do espaçamento de plantio, e

Ea - eficiência de aplicação do sistema de irrigação (90\%).

Para o cálculo da precipitação efetiva, foi considerado o valor da capacidade real de água no solo que, para as condições da área experimental, é $20 \mathrm{~mm}$. Foram utilizados diferentes valores de Kc em função dos dias após o transplantio (DAT). Até os 120 DAT, utilizou-se do Kc de 0,80, chegando a 1,50 no período de 241 a 360 DAT. A partir de outubro-2005, quando a cultura completou aproximadamente 12 meses após o transplantio (DAT $=360$ dias), em função do excesso de chuvas que causou aumento de doenças no solo (phtophthora) e, conseqüentemente, perda de plantas, as lâminas de irrigação foram modificadas, reduzindo o valor de Kc para 1,30.

Para avaliar a produtividade comercial, foram realizadas colheitas no período de julho-2005 a junho-2006, totalizando 11 meses e 21 dias, com intervalo médio de dez dias. Os frutos foram colhidos quando atingiram o estádio I de maturação. Após a colheita, os frutos foram contados, pesados e separados em função do padrão comercial e não-comercial. Foram considerados frutos comerciais aqueles com massa $\geq 200$ g e não-eformados.

Para a determinação das características físicas, mediram-se o comprimento e o diâmetro de cinco frutos por repetição, escolhidos aleatoriamente, utilizando-se de paquímetro digital. Mensalmente, foram realizadas análises para a determinação do teor de sólidos solúveis totais (SST), firmeza do fruto e firmeza da polpa.

Para a determinação da firmeza do fruto, foram selecionados três pontos, eqüidistantes, na altura do terço médio do fruto (pouco abaixo da região equatorial, ao lado oposto do pedúnculo). Para a determinação da firmeza da polpa (expressa em $\mathrm{N}$ ), os frutos foram divididos em duas faces transversais, na altura da região de medição da firmeza do fruto, sendo essas medições realizadas diretamente na polpa do fruto. As leituras foram feitas utilizando penetrômetro digital de bancada (Fruit Pressure Tester, Taly; modelo 53205), com adaptador de altura 8,0 x 8,0 mm (altura x diâmetro).

O teor de sólidos solúveis totais (expresso em ${ }^{\circ}$ Brix) foi determinado por meio da extração do suco de uma amostra de tecido da polpa, a partir de extração por pressão manual. As leituras foram efetuadas por refratômetro manual (Sama - MT-032).

As análises estatísticas foram realizadas utilizando-se do software SAEG 7.0 (Sistema de Análises Estatísticas e Genéticas), da Universidade Federal de Viçosa. 


\section{RESULTADOS E DISCUSSÃO}

Na Tabela 3, têm-se as médias mensais de temperatura e de umidade relativa do ar, da precipitação e da evapotranspiração de referência (Penman-Monteith) do período de fevereiro-2005 a junho-2006, obtidas da estação micrometeorológica automática instalada na Fazenda. A temperatura média no período foi de $23,6{ }^{\circ} \mathrm{C}$, com máxima de $27{ }^{\circ} \mathrm{C}$ e mínima de $20,4{ }^{\circ} \mathrm{C}$. A umidade relativa média do ar no período foi de $93,1 \%$, variando de $87 \%$ a $96,8 \%$.

Durante os 17 meses de avaliação, apenas em nove meses as precipitações pluviométricas ocorridas foram inferiores às lâminas aplicadas $(\mathrm{I}+\mathrm{Pe})$; nos demais, as precipitações ultrapassaram as necessidades hídricas das plantas. Devido ao excesso de chuvas, os valores de lâminas aplicadas $\left(\mathrm{I}+\mathrm{Pe}\right.$ ) nos tratamentos $\mathrm{L}_{2}, \mathrm{~L}_{3}, \mathrm{~L}_{4}$ e $\mathrm{L}_{5}$ foram apenas $8 ; 17 ; 23$ e $30 \%$ maior do que a lâmina aplicada no tratamento $\mathrm{L}_{1}$. A lâmina aplicada $(\mathrm{I}+\mathrm{Pe})$ de $1.525 \mathrm{~mm}$, correspondente ao tratamento $\mathrm{L}_{4}$, foi a que mais se aproximou dos $1.500 \mathrm{~mm}$, valor proposto por BERNARDO et al. (1996).

TABELA 3. Dados climáticos da área experimental do período da sexagem até o final do experimento. Climatic data of the experimental area from the period of sexation until the end of the experiment.

\begin{tabular}{cccccc}
\hline Mês & Dias & Temperatura Média $\left({ }^{\circ} \mathrm{C}\right)$ & UR $(\%)$ & Precipitação $(\mathrm{mm})$ & ETo $\left(\mathrm{mm}\right.$ mês $\left.{ }^{-1}\right)$ \\
\hline fev.-2005 & 28 & 25,5 & 92,6 & 179 & 78,8 \\
mar.-2005 & 31 & 25,6 & 94,2 & 218 & 81,5 \\
abr.-2005 & 30 & 24,5 & 94,2 & 83 & 72,8 \\
maio-2005 & 31 & 23,0 & 94,7 & 189 & 42,4 \\
jun.-2005 & 30 & 21,5 & 96,9 & 228 & 45,7 \\
jul.-2005 & 31 & 20,6 & 94,5 & 25 & 60,2 \\
ago.-2005 & 31 & 21,6 & 94,1 & 17 & 66,1 \\
set.-2005 & 30 & 22,1 & 95,1 & 88 & 55,7 \\
out.-2005 & 31 & 24,2 & 90,5 & 38 & 109,0 \\
nov.-2005 & 30 & 23,4 & 95,7 & 283 & 60,8 \\
dez.-2005 & 31 & 24,6 & 93,2 & 138 & 95,6 \\
jan.-2006 & 31 & 25,5 & 89,7 & 64 & 132,9 \\
fev.-2006 & 28 & 27,0 & 87,0 & 38 & 122,9 \\
mar.-2006 & 31 & 25,7 & 93,9 & 275 & 87,0 \\
abr.-2006 & 30 & 24,5 & 94,0 & 88 & 83,0 \\
maio-2006 & 31 & 21,9 & 92,0 & 26 & 76,6 \\
jun.-2006 & 28 & 20,4 & 90,0 & 44 & 59,0 \\
\hline Total/Média & 513 & 23,6 & 93,1 & 2.021 & 1.330 \\
\hline
\end{tabular}

Na Tabela 4, tem-se o resumo das análises de variância da massa média dos frutos, do número de frutos por planta e da produtividade. Embora tenha havido efeito significativo para o peso do fruto, não foi possível, por meio da análise de regressão, ajustar função de produção para estimar o peso médio do fruto em função das lâminas aplicadas.

A massa média dos frutos foi de $404 \mathrm{~g}$, o qual ficou dentro do padrão de aceitação dos mercados interno e externo, uma vez que cada país tem exigências diferentes quanto ao peso e ao tamanho dos frutos. O mercado suíço tem preferência por frutos na faixa de 290 a $349 \mathrm{~g}$, os mercados alemão e francês, por frutos na faixa de 350 a $439 \mathrm{~g}$, e o português, por frutos maiores, variando de 449 a $650 \mathrm{~g}$ (BALBINO \& COSTA, 2003).

A produtividade média observada em 11 meses e 21 dias de colheita foi de $79,4 \mathrm{t} \mathrm{ha}^{-1}$, não havendo diferença significativa entre os valores obtidos em função dos tratamentos; entretanto, em valores absolutos, a maior produtividade ocorreu para a combinação da lâmina aplicada de $1.525 \mathrm{~mm}$, com a dose de $42 \mathrm{~g}$ de $\mathrm{K}_{2} \mathrm{O}$ por planta ao mês $\left(\mathrm{L}_{4} \mathrm{~K}_{2}\right)$, de $96,4 \mathrm{t} \mathrm{ha}^{-1}$, os quais foram superiores à produtividade média da cultura do mamão no Espírito Santo, de $72 \mathrm{t} \mathrm{ha}^{-1}$. SILVA et al. 
(2001) obtiveram uma produtividade máxima do mamoeiro Sunrise solo, em seis meses de colheita de 30,9 $\mathrm{t} \mathrm{ha}^{-1}$ quando a lâmina aplicada foi de $2.731 \mathrm{~mm}$. Já OLIVEIRA \& CALDAS (2004) obtiveram, em 12 meses de colheita, produtividade máxima do mamoeiro Sunrise solo de 99,53 $\mathrm{t} \mathrm{ha}^{-1}$ para a adubação de 272; 136 e $272 \mathrm{~g}$ de $\mathrm{K}_{2} \mathrm{O}$ planta ${ }^{-1}$ de $\mathrm{N}, \mathrm{P}_{2} \mathrm{O}_{5}$ e $\mathrm{K}_{2} \mathrm{O}$, respectivamente.

TABELA 4. Valores de massa média, número de frutos por planta e produtividade do mamoeiro cv. Golden em 11 meses e 21 dias de colheita. Values of average weight, number of fruits per plant and productivity of papaya tree, cultivar Golden, in 11 months and 21 days of harvest.

\begin{tabular}{|c|c|c|c|}
\hline Tratamentos & Massa de Frutos (g) & Número de Frutos (frutos planta ${ }^{-1}$ ) & Produtividade $\left(\mathrm{t} \mathrm{ha}^{-1}\right)$ \\
\hline $\mathrm{L}_{1} \mathrm{~K}_{1}$ & 402 & 104 & 84,9 \\
\hline $\mathrm{L}_{1} \mathrm{~K}_{2}$ & 391 & 93 & 75,0 \\
\hline $\mathrm{L}_{1} \mathrm{~K}_{3}$ & 401 & 92 & 76,0 \\
\hline $\mathrm{L}_{1} \mathrm{~K}_{4}$ & 395 & 105 & 85,2 \\
\hline $\mathrm{L}_{2} \mathrm{~K}_{1}$ & 394 & 97 & 77,4 \\
\hline $\mathrm{L}_{2} \mathrm{~K}_{2}$ & 395 & 91 & 73,6 \\
\hline $\mathrm{L}_{2} \mathrm{~K}_{3}$ & 392 & 87 & 69,4 \\
\hline $\mathrm{L}_{2} \mathrm{~K}_{4}$ & 384 & 73 & 57,3 \\
\hline $\mathrm{L}_{3} \mathrm{~K}_{1}$ & 397 & 98 & 79,4 \\
\hline $\mathrm{L}_{3} \mathrm{~K}_{2}$ & 404 & 98 & 79,9 \\
\hline $\mathrm{L}_{3} \mathrm{~K}_{3}$ & 394 & 94 & 75,5 \\
\hline $\mathrm{L}_{3} \mathrm{~K}_{4}$ & 413 & 109 & 92,2 \\
\hline $\mathrm{L}_{4} \mathrm{~K}_{1}$ & 422 & 100 & 84,1 \\
\hline $\mathrm{L}_{4} \mathrm{~K}_{2}$ & 435 & 109 & 96,4 \\
\hline $\mathrm{L}_{4} \mathrm{~K}_{3}$ & 423 & 96 & 82,2 \\
\hline $\mathrm{L}_{4} \mathrm{~K}_{4}$ & 418 & 98 & 83,7 \\
\hline $\mathrm{L}_{5} \mathrm{~K}_{1}$ & 404 & 115 & 96,5 \\
\hline $\mathrm{L}_{5} \mathrm{~K}_{2}$ & 411 & 91 & 74,8 \\
\hline $\mathrm{L}_{5} \mathrm{~K}_{3}$ & 400 & 88 & 70,1 \\
\hline $\mathrm{L}_{5} \mathrm{~K}_{4}$ & 407 & 92 & 75,0 \\
\hline Média & 404 & 96 & 79,4 \\
\hline Teste F & $*$ & n.s. & n.s. \\
\hline C.V. $(\%)$ & 3,51 & 12,6 & 14,8 \\
\hline
\end{tabular}

* - significativo a $5 \%$ de probabilidade, pelo teste $\mathrm{F}(\mathrm{p}<0,05)$; n.s. - não-significativo a $5 \%$ de probabilidade $(\mathrm{p}<0,05)$.

A ausência de resposta dos parâmetros de produtividade aos tratamentos pode ser explicada pelo volume $(2.021 \mathrm{~mm})$ e pela distribuição das chuvas ocorridas, que, durante o período de avaliação (17 meses), apenas em nove meses, as precipitações totais ocorridas foram inferiores às lâminas aplicadas $(\mathrm{I}+\mathrm{Pe})$, e nos demais meses, as precipitações totais ultrapassaram as necessidades hídricas do mamoeiro, que gira em torno de $1.500 \mathrm{~mm} \mathrm{ano}^{-1}$ (BERNARDO et al., 1996).

Na Figura 2, tem-se o comportamento da produtividade comercial obtida em função da média de todos os tratamentos em cada mês. Observa-se que, ao longo do ciclo produtivo, há grande variação na produtividade, ocorrendo picos de produção. De julho a outubro-2005, a produtividade mensal foi crescente, decrescendo a partir daí até março-2006, quando foi obtida a menor média mensal (3,02 $\left.\mathrm{t} \mathrm{ha}^{-1}\right)$. Os maiores picos ocorreram em setembro/2005 e maio/2006, que correspondem ao $3^{\mathrm{o}}$ e $11^{\mathrm{o}}$ meses do ciclo produtivo, quando foram colhidos 10,47 e $10,31 \mathrm{t} \mathrm{ha}^{-1}$, respectivamente, para os dois meses. GOMES FILHO (2005) verificou que as lâminas de irrigação influenciaram na produtividade do mamoeiro cv. Golden, no qual os maiores valores ocorreram nos meses de julho a setembro, quando se irrigou com lâmina equivalente a 100\% da ETo. 
O número médio de frutos por planta no período de 11 meses e 21 dias de colheita foi de 96 , totalizando 190.464 frutos por ha. Apesar de não haver diferença significativa entre os tratamentos, a combinação da lâmina aplicada de $1.604 \mathrm{~mm}$ com a dose de $30 \mathrm{~g}$ de $\mathrm{K}_{2} \mathrm{O}$ por planta ao mês $\left(\mathrm{L}_{5} \mathrm{~K}_{1}\right)$, foi a que proporcionou maior número de frutos por planta (115), equivalendo a 228.160 frutos por ha.

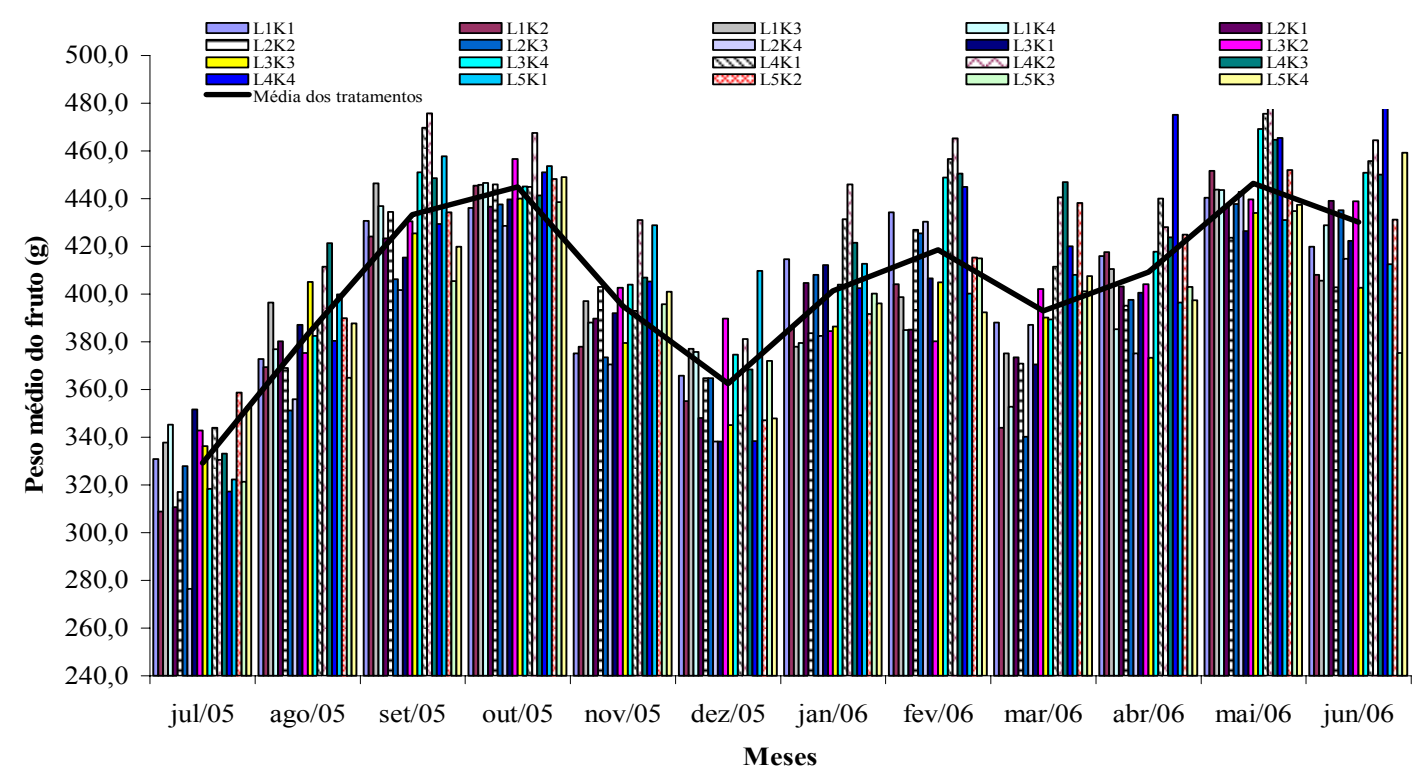

FIGURA 1. Distribuição da massa média dos frutos de mamão cv. Golden, ao longo de 11 meses e 21 dias de colheita (julho-2005 a junho-2006), Linhares - ES. Distribution of the average weight of papaya fruits, cultivar Golden, along the period of 11 months and 21 days of harvest (July, 2005 to June, 2006), Linhares - ES, Brazil.

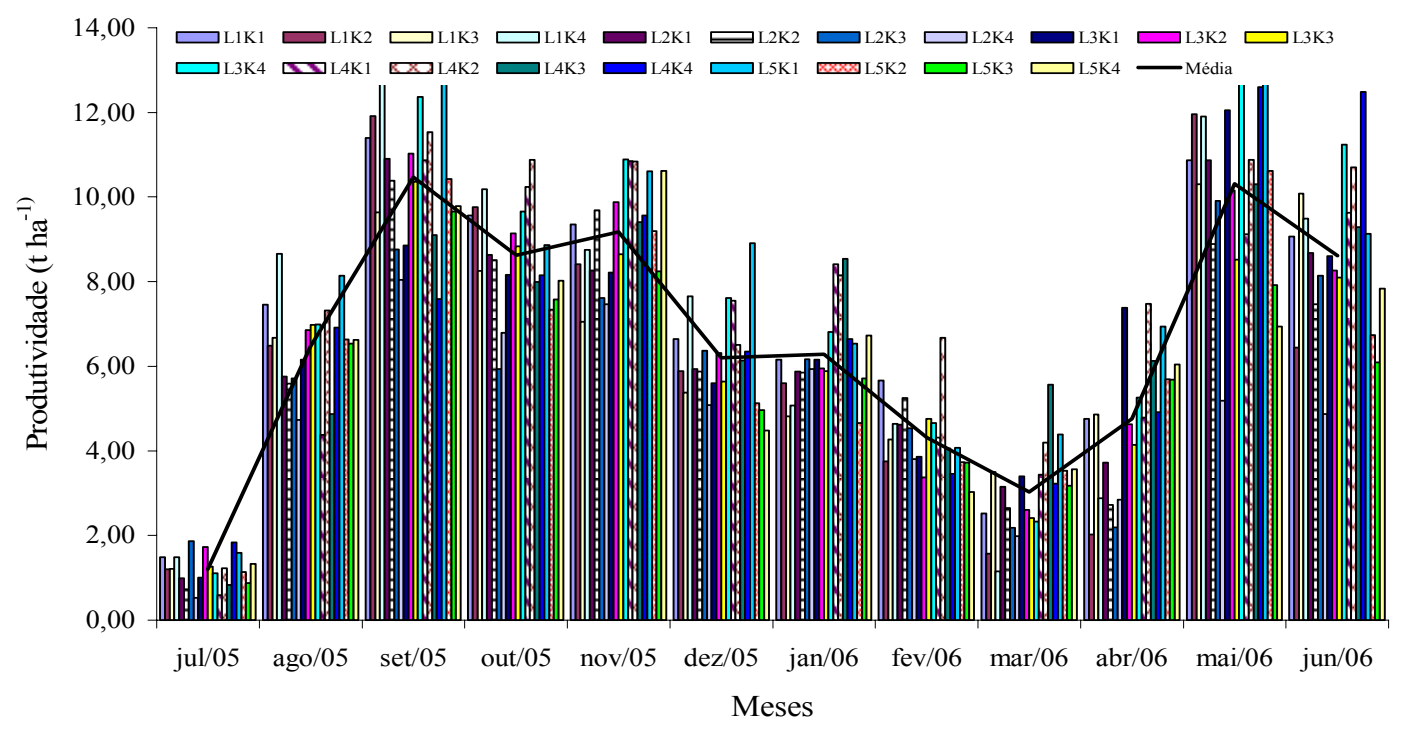

FIGURA 2. Distribuição da produtividade mensal do mamoeiro cultivar Golden, ao longo de 11 meses e 21 dias de colheita (julho-2005 a junho-2006), Linhares - ES. Distribution of the monthly productivity of the papaya tree, cultivar Golden, along the period of 11 months and 21 days of harvest (July, 2005 to June, 2006), Linhares - ES, Brazil. 
Os tratamentos não exerceram efeitos estatisticamente diferentes sobre os parâmetros analisados de qualidade do fruto, conforme evidenciado na Tabela 5. O valor médio do teor de SST dos frutos analisados no estádio de maturação I foi de $10,11^{\circ}$ Brix. As determinações dos teores de SST, neste trabalho, foram realizadas em frutos no estádio de maturação I, o que implica valores sempre abaixo do SST de frutos no estádio III. De acordo com dados fornecidos pela Caliman Agrícola, do estádio de maturação I para o III, normalmente ocorre acréscimo no teor de SST de 1,0 a $2,5^{\circ}$ Brix.

Os valores obtidos ficaram abaixo dos valores da área comercial da Fazenda Caliman Agrícola, de $12,17^{\circ}$ Brix, durante o mesmo período experimental e abaixo do teor mínimo exigido pelo mercado internacional, que é de $11,5^{\circ}$ Brix, referindo-se a frutos no estádio de maturação III. Os baixos valores de SST obtidos no experimento podem ter ocorrido devido à forma de adubação ter sido por cobertura, uma vez que, devido ao excesso de chuvas, os adubos podem ter sido lixiviados, não sendo absorvidos pelas plantas. BORN et al. (2006) e SOUZA (2004) obtiveram valores de SST em frutos de mamão cv. Golden, no estádio I de maturação, de 11,6 e 11,9 ${ }^{\circ}$ Brix, respectivamente, em condições de cultivo da área comercial da Fazenda Caliman Agrícola.

TABELA 5. Valores médios de sólidos solúveis totais (SST), firmeza da polpa e do fruto, diâmetro e comprimento de frutos do mamoeiro cv. Golden, para as condições experimentais, no período de 11 meses e 21 dias de colheita. Average values of total soluble solids content, pulp and fruit firmness, diameter and length of the fruits of the papaya tree, cultivar Golden, for the experimental conditions in the period from 11 months and 21 days of harvest.

\begin{tabular}{cccccc}
\hline \multirow{2}{*}{ Tratamentos } & $\begin{array}{c}\text { SST } \\
\left({ }^{\circ} \text { Brix }\right)\end{array}$ & $\begin{array}{c}\text { Firmeza da Polpa Firmeza do Fruto } \\
(\mathrm{N})\end{array}$ & $\begin{array}{c}\text { Comprimento do } \\
\text { Fruto }(\mathrm{mm})\end{array}$ & $\begin{array}{c}\text { Diâmetro do Fruto } \\
(\mathrm{mm})\end{array}$ \\
\hline $\mathrm{L}_{1} \mathrm{~K}_{1}$ & 10,03 & 83,3 & 128,0 & 135,5 & 84,5 \\
$\mathrm{~L}_{1} \mathrm{~K}_{2}$ & 10,03 & 80,4 & 135,7 & 135,6 & 83,3 \\
$\mathrm{~L}_{1} \mathrm{~K}_{3}$ & 10,08 & 79,4 & 119,7 & 136,2 & 83,3 \\
$\mathrm{~L}_{1} \mathrm{~K}_{4}$ & 10,06 & 81,9 & 120,2 & 136,9 & 84,6 \\
$\mathrm{~L}_{2} \mathrm{~K}_{1}$ & 10,04 & 78,5 & 122,6 & 135,9 & 83,6 \\
$\mathrm{~L}_{2} \mathrm{~K}_{2}$ & 10,33 & 80,7 & 134,8 & 133,5 & 82,5 \\
$\mathrm{~L}_{2} \mathrm{~K}_{3}$ & 10,31 & 78,5 & 131,2 & 135,3 & 83,5 \\
$\mathrm{~L}_{2} \mathrm{~K}_{4}$ & 10,08 & 78,4 & 127,5 & 136,6 & 83,1 \\
$\mathrm{~L}_{3} \mathrm{~K}_{1}$ & 10,02 & 80,4 & 121,9 & 140,1 & 86,0 \\
$\mathrm{~L}_{3} \mathrm{~K}_{2}$ & 10,23 & 79,2 & 123,5 & 136,3 & 83,6 \\
$\mathrm{~L}_{3} \mathrm{~K}_{3}$ & 10,01 & 80,4 & 130,0 & 136,4 & 84,3 \\
$\mathrm{~L}_{3} \mathrm{~K}_{4}$ & 10,16 & 79,6 & 127,2 & 133,6 & 82,8 \\
$\mathrm{~L}_{4} \mathrm{~K}_{1}$ & 10,24 & 78,6 & 121,6 & 134,3 & 83,1 \\
$\mathrm{~L}_{4} \mathrm{~K}_{2}$ & 10,00 & 76,2 & 124,1 & 138,0 & 85,0 \\
$\mathrm{~L}_{4} \mathrm{~K}_{3}$ & 10,07 & 77,2 & 124,2 & 134,4 & 82,8 \\
$\mathrm{~L}_{4} \mathrm{~K}_{4}$ & 10,20 & 79,1 & 127,7 & 135,3 & 83,7 \\
$\mathrm{~L}_{5} \mathrm{~K}_{1}$ & 10,05 & 83,2 & 132,7 & 134,2 & 82,1 \\
$\mathrm{~L}_{5} \mathrm{~K}_{2}$ & 10,25 & 79,2 & 123,8 & 137,6 & 84,3 \\
$\mathrm{~L}_{5} \mathrm{~K}_{3}$ & 10,07 & 80,7 & 124,4 & 135,8 & 83,9 \\
$\mathrm{~L}_{5} \mathrm{~K}_{4}$ & 9,97 & 80,8 & 123,3 & 135,5 & 84,0 \\
\hline $\mathrm{Mé}_{1 i a}$ & 10,11 & 79,8 & 126,2 & 135,9 & 83,7 \\
Teste F & n.s. & n.s. & n.s. & n.s. & n.s. \\
$\mathrm{C}_{\text {.V }} .(\%)$ & 2,42 & 3,4 & 5,6 & 1,3 & 1,9 \\
\hline
\end{tabular}

* - significativo a $5 \%$ de probabilidade, pelo teste $\mathrm{F}(\mathrm{p}<0,05)$; n.s. - não-significativo a $5 \%$ de probabilidade $(\mathrm{p}<0,05)$.

A firmeza média da polpa e do fruto no estádio I de maturação foi de 79,8 e 126,2 N, respectivamente, não havendo influência das lâminas aplicadas e das doses de potássio, o que, possivelmente, se deu em virtude do excesso de chuvas e da pequena variação entre as lâminas 
aplicadas. GOMES FILHO (2005) também verificou que as lâminas aplicadas, variando de 50 a $150 \%$ da ETo, não influenciaram na firmeza dos frutos do mamoeiro cv. Golden. Já DAMATO JÚNIOR et al. (2000) verificaram que as plantas de pimentão-amarelo irrigadas com a lâmina de $120 \%$ da evaporação do tanque classe A (ECA) produziram frutos mais firmes do que as plantas irrigadas com a lâmina de $50 \%$ da ECA; isso é devido à quantidade de água aplicada, deixando as células do vegetal mais túrgidas, ou seja, frutos que receberam mais água foram os que se apresentaram mais firmes.

O comprimento e o diâmetro médio dos frutos foram de 135,9 e 83,7 mm, respectivamente. Valores aproximados de $134,3 \mathrm{~mm}$ de comprimento e $76,1 \mathrm{~mm}$ de diâmetro foram obtidos por FONSECA (2001), em experimento com a cultivar "Sunrise solo", em função de lâminas de irrigação e de doses de $\mathrm{K}_{2} \mathrm{O}$.

\section{CONCLUSÕES}

As lâminas aplicadas (irrigação + precipitação efetiva) de 1.230 a $1.600 \mathrm{~mm}$ e as doses de potássio de 30 a $66 \mathrm{~g}$ de $\mathrm{K}_{2} \mathrm{O}$ por planta ao mês não influenciaram $(\mathrm{P}<0,05)$ nos parâmetros de produção, com exceção do peso médio dos frutos e nas características físicas e químicas dos frutos. Considerando os valores absolutos, observou-se que a maior produtividade ocorreu para a combinação da lâmina aplicada de $1.525 \mathrm{~mm}$, com a dose de $42 \mathrm{~g}$ de $\mathrm{K}_{2} \mathrm{O}$ por planta ao mês $\left(\mathrm{L}_{4} \mathrm{~K}_{2}\right)$, de $96,4 \mathrm{t} \mathrm{ha}^{-1}$.

\section{AGRADECIMENTOS}

À UENF, pela concessão da bolsa de estudos e pela oportunidade de realização do curso; à Financiadora de Estudos e Projetos (FINEP), e à Caliman Agrícola S.A., pelo apoio, infra-estrutura e oportunidade de realizar os experimentos.

\section{REFERÊNCIAS}

ALLEN, R.G.; PEREIRA, L.S.; RAES, D.; SMITH, M. Crop evapotranspiration: guidelines for computing crop water requirements. Rome: FAO, 1998. (Irrigation and Drainage Paper, 56).

ALMEIDA, F.T. de; BERNARDO, S.; SOUSA, E.F. de; MARIN, S.L.D.; GRIPPA, S. Growth and yield of papaya under irrigation. Scientia Agrícola, Piracicaba, v.60, n.3, p.419-24, 2003.

BALBINO, J.M.S.; COSTA, A.F.S. Crescimento e desenvolvimento dos frutos do mamoeiro do "grupo solo" e padrão de qualidade. In: MARTINS, D. dos S.; COSTA, A.F.S. da. (Ed.) A cultura do mamoeiro: tecnologias de produção. Vitória: INCAPER, 2003. p.389-402.

BERNARDO, S.; CARVALHO, J.A.; SOUSA, E.F. Irrigação do mamoeiro. Campos dos Goytacazes: UENF, 1996. 20 p. (Boletim Técnico, 5)

BORN, I.U.; JACOMINO, A.P.; TEVEISAN, M.J. Fisiologia do amadurecimento e qualidade do mamão "Golden" colhido em diferentes estádios de maturação. In: CONGRESSO BRASILEIRO DE FRUTICULTURA, 19., 2006, Cabo Frio. Anais... SBF/UENF/UFRuralRJ, 2006. p.545.

COELHO, E.F.; SILVA, J.G.F. Irrigação do mamaoeiro. In: MARTINS, D.S.; COSTA, A.F.S. (Org.). A cultura do mamoeiro: tecnologia de produção. Vitória: DCM Incaper, 2003. v.1, p.163-97.

DAMATTO JÚNIOR, E.R.; RODRIGUES, D.S.; VICENTINI, N.M.; GOTO, R. Qualidade póscolheita de frutos de pimentão amarelo sob diferentes lâminas de água e cobertura do solo.

Horticultura Brasileira, Brasília, v.18, n.1, p.206-8, 2000. (Suplemento 2)

FAGUNDES, G.R.; YAMANISHI, O.K. Características físicas e químicas de frutos de mamoeiro do grupo "solo" comercializados em quatro estabelecimentos de Brasília - DF. Revista Brasileira de Fruticultura, Jaboticabal, v.23, n.3, p.541-5, 2001. 
FONSECA, K.M. Resposta da cultura do mamoeiro (Carica papaya L.) a níveis de potássio e de água. 2001. 125 f. Dissertação (Mestrado em Ciências Agrárias) - Universidade de Brasília, Brasília, 2001.

GOMES FILHO, A. Ocorrência da mancha fisiológica do mamão (Carica papaya L.) sob diferentes lâminas de irrigação e cobertura do solo. 2005. 83 f. Dissertação (Mestrado em Produção Vegetal) - Universidade Estadual do Norte Fluminense, Campos dos Goytacazes, 2005.

MALAVOLTA, E.; VITTI, G.C.; OLIVEIRA, S.A de. Avaliação do estado nutricional das plantas: princípios e aplicações. 2.ed. Piracicaba: POTAFOS, 1997. 319 p.

MARTINS, D.S.; COSTA, A. de F. A cultura do mamoeiro: tecnologia de produção. Vitória: INCAPER, 2003. 497 p.

OLIVEIRA, A.M.G.; CALDAS, R.C. Produção do mamoeiro em função de adubação com nitrogênio, fósforo e potássio. Revista Brasileira de Fruticultura, Jaboticabal, v.26, n.1, p.160-3, 2004.

OLIVEIRA, A.M.G.; SOUZA, L.F. da S.; RAIJ, B.V.; MAGALHÃES, E.F.J.; BERNARDI, A.C. de C. Nutrição, calagem e adubação do mamoeiro irrigado. Cruz das Almas: Embrapa Mandioca e Fruticultura, 2004. 10 p. (Circular Técnica, 69).

ROLLIN, S.G.; COUTO, H.T.Z.; JESUS, R.M. Mortalidade e recrutamento de árvores na Floresta Atlântica de Linhares - ES. Scientia Forestalis, Piracicaba, v.55, n.1, p.49-69, 1999.

SANTOS, F.S.S. Diferentes lâminas de irrigação e doses de nitrato de potássio, aplicados via fertirrigação, sobre a cultura do mamão. 2006. 65 f. Dissertação (Mestrado em Irrigação e Drenagem) - Universidade Federal do Ceará, Fortaleza, 2006.

SIAG. Sistema de Informações Agrometeorológico do Estado do Espírito Santo: Disponível em: <www.siag.incaper.es.gov.br/index.htm>. Acesso em: 10 dez. 2006.

SILVA, T.S.M.; COELHO, E.F.; PAZ, V.P. da S.; COELHO FILHO, M.A.; SOUZA, E.A. Efeito da interação entre $\mathrm{N}, \mathrm{K}_{2} \mathrm{O}$ e irrigação na produtividade do mamoeiro no primeiro ano nas condições do Recôncavo Baiano. Cruz das Almas: Universidade Federal da Bahia, 2003. 4 p.

SILVA, J.G.F.da; FERREIRA, P.A.; COSTA, L.C.; MELENDES, R.R.V.; CECOM, P.R. Efeitos de diferentes lâminas e freqüências de irrigação sobre a produtividade do mamoeiro (Carica papaya L.). Revista Brasileira de Fruticultura, Jaboticabal, v.23, n.3, p.597-601, 2001.

SOUZA, L.M. de. Algumas características fisicas e químicas de mamões (Carica papaya L.) dos grupos "formosa" (Tainung 01) e "solo" (Golden) com e sem mancha fisiológica colhidos em diferentes estádios de maturação. 2004. 103 f. Dissertação (Mestrado em Produção Vegetal) Universidade Estadual do Norte Fluminense, Campos dos Goytacazes, 2004.

VITTI, G.C. Nutrição e adubação do mamoeiro. In: SIMPÓSIO BRASILEIRO SOBRE A CULTURA DO MAMOEIRO, 2., 1989, Jaboticabal. Anais... Jaboticabal: UNESP-FCAV, 1989. p.121-59. 